\title{
Wild-type FUS corrects ALS-like disease induced by cytoplasmic mutant FUS through autoregulation
}

Inmaculada Sanjuan-Ruiz ${ }^{1}$, Noé Govea-Perez ${ }^{2 \dagger}$, Melissa McAlonis-Downes ${ }^{2 \dagger}$, Stéphane Dieterle ${ }^{1}$, Salim Megat ${ }^{1}$, Sylvie Dirrig-Grosch ${ }^{1}$, Gina Picchiarelli ${ }^{1}$, Diana Piol ${ }^{3}$, Qiang Zhu' ${ }^{2}$, Brian Myers ${ }^{2}$, Chao-Zong Lee ${ }^{4,5}$, Don W Cleveland ${ }^{2}$, Clotilde Lagier-Tourenne ${ }^{4,5}$, Sandrine Da Cruz ${ }^{2,3^{*}}$ and Luc Dupuis ${ }^{1 *}$

\begin{abstract}
Mutations in FUS, an RNA-binding protein involved in multiple steps of RNA metabolism, are associated with the most severe forms of amyotrophic lateral sclerosis (ALS). Accumulation of cytoplasmic FUS is likely to be a major culprit in the toxicity of FUS mutations. Thus, preventing cytoplasmic mislocalization of the FUS protein may represent a valuable therapeutic strategy. FUS binds to its own pre-mRNA creating an autoregulatory loop efficiently buffering FUS excess through multiple proposed mechanisms including retention of introns 6 and/or 7. Here, we introduced a wild-type FUS gene allele, retaining all intronic sequences, in mice whose heterozygous or homozygous expression of a cytoplasmically retained FUS protein (Fus ${ }^{\Delta L S}$ ) was previously shown to provoke ALS-like disease or postnatal lethality, respectively. Wild-type FUS completely rescued the early lethality caused by the two Fus ${ }^{\Delta N L S}$ alleles, and improved the age-dependent motor deficits and reduced lifespan caused by heterozygous expression of mutant FUS ${ }^{\triangle N L S}$. Mechanistically, wild-type FUS decreased the load of cytoplasmic FUS, increased retention of introns 6 and 7 in the endogenous mouse Fus mRNA, and decreased expression of the mutant mRNA. Thus, the wild-type FUS allele activates the homeostatic autoregulatory loop, maintaining constant FUS levels and decreasing the mutant protein in the cytoplasm. These results provide proof of concept that an autoregulatory competent wild-type FUS expression could protect against this devastating, currently intractable, neurodegenerative disease.
\end{abstract}

Keywords: Amyotrophic lateral sclerosis, Fronto-temporal dementia, Mouse models, RNA-binding proteins, FUS, Autoregulation, Therapy

\footnotetext{
*Correspondence: sandrine.dacruz@kuleuven.be; Idupuis@unistra.fr

${ }^{\dagger}$ Noé Govea-Perez and Melissa McAlonis-Downes contributed equally to the work.

${ }^{2}$ Ludwig Institute for Cancer Research, University of California at San Diego,

La Jolla, USA

'Mécanismes centraux et périphériques de la neurodégénérescence, Centre

de Recherches en Biomédecine, Université de Strasbourg, Inserm,

UMR-S1118, Strasbourg, France

Full list of author information is available at the end of the article
}

(C) The Author(s). 2021 Open Access This article is licensed under a Creative Commons Attribution 4.0 International License, which permits use, sharing, adaptation, distribution and reproduction in any medium or format, as long as you give appropriate credit to the original author(s) and the source, provide a link to the Creative Commons licence, and indicate if changes were made. The images or other third party material in this article are included in the article's Creative Commons licence, unless indicated otherwise in a credit line to the material. If material is not included in the article's Creative Commons licence and your intended use is not permitted by statutory regulation or exceeds the permitted use, you will need to obtain permission directly from the copyright holder. To view a copy of this licence, visit http://creativecommons.org/licenses/by/4.0/ The Creative Commons Public Domain Dedication waiver (http://creativecommons.org/publicdomain/zero/1.0/) applies to the data made available in this article, unless otherwise stated in a credit line to the data. 


\section{Background}

Amyotrophic lateral sclerosis (ALS), the major adult onset motor neuron disease $[1,2]$, is characterized by a progressive paralysis leading to death within a few years after onset. Mutations in FUS cause the most severe cases of ALS, with young onset and rapid disease progression [3, 4]. FUS mutations are clustered in the Cterminal region of the protein, carrying a PY-nuclear localization sequence (NLS), responsible for its nuclear import. Truncating mutations have been described in ALS families, leading to complete loss of the PY-NLS, and cytoplasmic aggregation of FUS [5, 6]. Studies in mouse models have demonstrated that cytoplasmic accumulation of FUS provokes motor neuron degeneration [7-12]. Indeed, heterozygous Fus knock-in mice with ALS-like truncating mutations develop mild, late onset muscle weakness and motor neuron degeneration, while haploinsufficient Fus knock-out mice do not show ALS related symptoms [10-12]. A successful therapeutic strategy for FUS-ALS may lie in reduction of the cytoplasmic FUS content, to avoid its toxic effects.

FUS levels are regulated by other RNA-binding proteins $[13,14]$ and are tightly controlled by autoregulatory mechanisms [14-16]. Indeed, the addition of more than 20 copies of the complete human FUS gene to the mouse genome only slightly increases FUS protein levels, and does not lead to phenotypic consequences [8], showing the efficacy of this buffering system of FUS levels. Contrastingly, the saturation of FUS autoregulation, through overexpression of cDNA driven, autoregulatory incompetent, FUS expression, is highly toxic to neurons [9, 17]. FUS autoregulation appears to involve at least three possible mechanisms, including exon skipping [15], intron retention [14] and microRNA [16], and recent evidence suggested that the major autoregulatory mechanism was retention of introns 6 and 7 [14]. Here, we tested the hypothesis that the expression of a wild-type FUS gene, carrying all regulatory elements necessary for autoregulation would engage autoregulation of the mutation carrying RNA, and subsequently decrease accumulation of FUS in the cytoplasm.

\section{Results}

Wild-type FUS transgene rescues lethality and motor defects in Fus ${ }^{\Delta \mathrm{NLS}}$ mice

Human wild-type FUS transgenic mice (hFUS mice) expressing human FUS gene including its own human FUS promoter obtained from a BAC [8] were crossed with $\mathrm{Fus}^{\Delta \mathrm{NLS}}$ mice [11] in a two-round mating (Fig. $1 \mathrm{~A}$ ). As previously described, Fus ${ }^{\Delta \mathrm{NLS} / \Delta \mathrm{NLS}}$ mice (in absence of hFUS) die within the first hours after birth [11] and no homozygous mutant Fus ${ }^{\Delta \mathrm{NLS}}$ mice were obtained at 1 month of age in the absence of hFUS (Fig. 1B). Contrastingly, expression of hFUS transgene completely rescued lethality of homozygous $F u s^{\Delta \mathrm{NLS} / \Delta \mathrm{NLS}}$ mice until adulthood (Fig. 1 C). However, rescued homozygous $F_{u s}{ }^{\Delta N L S / \triangle N L S}$ mice displayed higher lethality throughout adulthood than wild-type littermate animals (Fig. 1 C). Increased adult lethality was also observed in Fus ${ }^{\Delta \mathrm{NLS} /+}$ mice, with about a $30 \%$ of death rate before 600 days of age $\left(\mathrm{p}=0.0398, \log\right.$ rank, Fus ${ }^{+/+}$vs. Fus $\left.{ }^{\Delta \mathrm{NLS} /+}\right)$, consistent with findings reported in another heterozygous knock-in model [10]. Nonetheless, most $\mathrm{Fus}^{\mathrm{\Delta NL} /+} /$ hFUS mice survived until this age, and their survival rate was indistinguishable from non-transgenic normal mice ( $p=$ $0.33 \mathrm{Fus}^{+/+}$vs. Fus ${ }^{\Delta \mathrm{NLS} /+} / \mathrm{hFUS}$ ) or from single hFUS transgenic mice (Fig. 1D). The mild, late onset, muscle weakness observed in Fus ${ }^{\Delta \mathrm{NLS} /+}$ mice using inverted grid test [12], was rescued in $\mathrm{Fus}^{\mathrm{\Delta LS} /+} / \mathrm{hFUS}$ and in Fus $^{\Delta \mathrm{NLS} / \Delta \mathrm{NLS}} /$ hFUS mice (Fig. 1E and Fig. S1A). Furthermore, hindlimb grip strength deficits associated with expression of Fus ${ }^{\Delta \mathrm{NLS} /+}$ were mildly and transiently improved in Fus ${ }^{\Delta \mathrm{NLS} /+} /$ hFUS females (Fig. $1 \mathrm{~F}$ ) but not in males (Fig. $1 \mathrm{~F}$ ). Indeed, in this test, the performance of hFUS transgenic mice decreased significantly in males after 10 months of age, thus confounding a potential protection (Fig. $1 \mathrm{~F}$ and Fig. S1A). These protective effects were not caused or modified by changes in body weight as there were no significant changes in body weight across genotypes before 200 days of age. After this age, only Fus ${ }^{\Delta \mathrm{NLS} / \Delta \mathrm{NLS}} /$ hFUS mice showed a mildly decreased body weight as compared to the wild-type and Fus $^{\Delta \mathrm{NLS} /+}$ mice (Fig. S1B). Thus, wild-type human FUS significantly rescued lethality and, at least partially, motor deficits associated with cytoplasmically retained mutant FUS ${ }^{\Delta N L S}$ protein.

\section{Wild-type FUS transgene decreases cytoplasmic accumulation of FUS in Fus ${ }^{\Delta \mathrm{NLS}}$ mice}

We then asked whether hFUS transgene altered levels of FUS in Fus ${ }^{\Delta \mathrm{NLS}}$ mice. Consistent with previous results [18], total FUS levels increased in Fus ${ }^{\Delta \mathrm{NLS} /+}$ mouse brains as compared to $\mathrm{Fus}^{+/+}$mice, and in $\mathrm{Fus}^{\mathrm{\Delta NLS} /+} / \mathrm{hFUS}$ as compared to single hFUS transgenic mice (Fig. 2 A-B). Consistent with previous results, the hFUS transgene on its own did not further increase total FUS proteins in wild type or Fus ${ }^{\Delta \mathrm{NLS} /+}$ mice. The increase observed in Fus $^{\Delta \mathrm{NLS} /+}$ mice was not detected when an antibody targeting the NLS sequence (C-term FUS), absent from the FUS ${ }^{\triangle \mathrm{NLS}}$ protein, was used, but was even more evident using an antibody targeting selectively mouse FUS (Fig. 2 A-B and Source data for uncropped western blots). This increase in mouse FUS was normalized by the hFUS transgene. Human FUS levels remained unchanged across the three genotypes carrying hFUS.

We then asked whether increased FUS cytoplasmic levels were also rescued by the hFUS transgene and performed subcellular fractionation to obtain nuclear and 

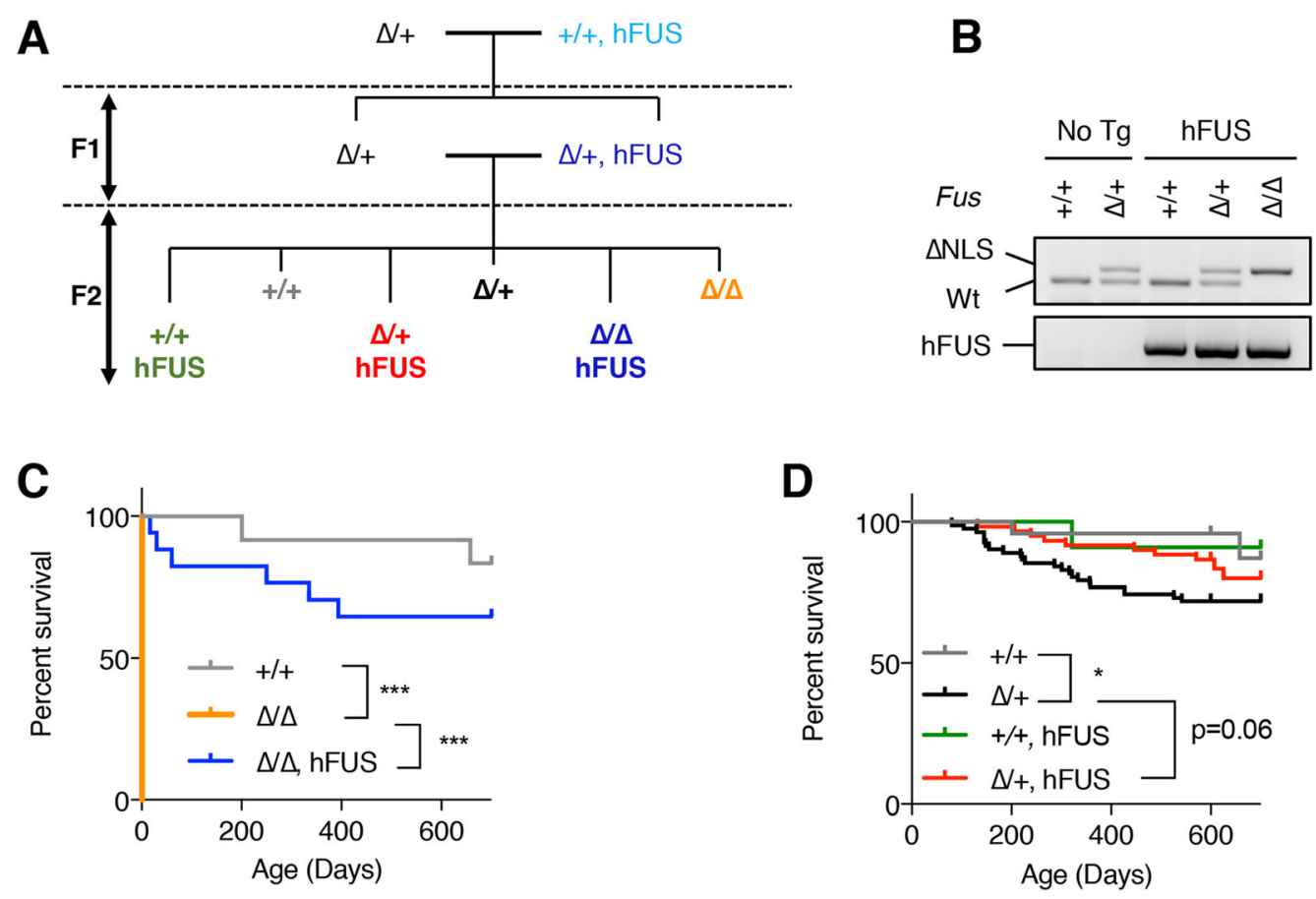

E

Inverted Grid
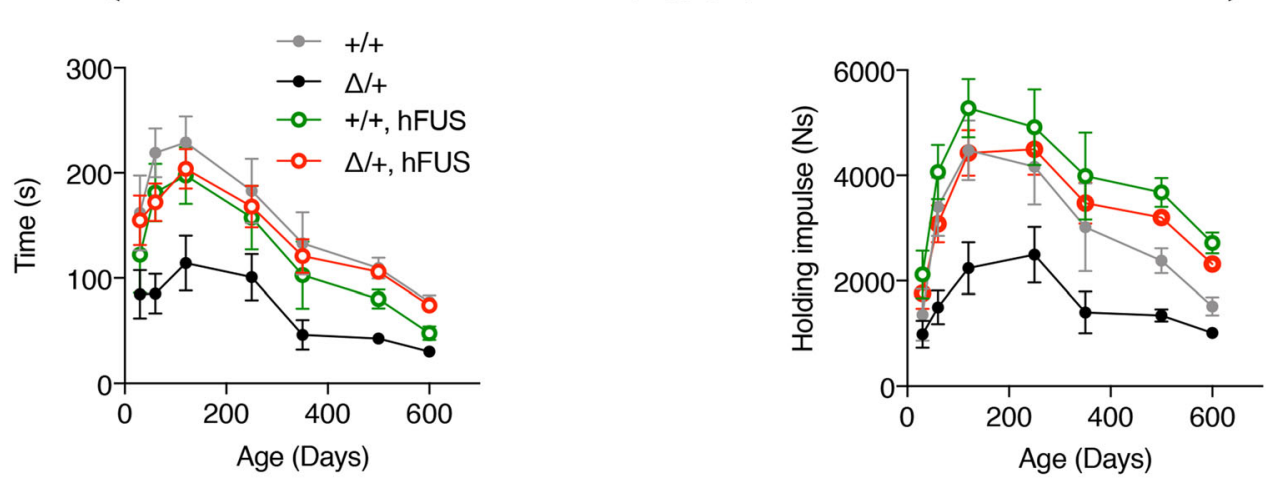

F

Hindlimb Grip Strength

Females

Males
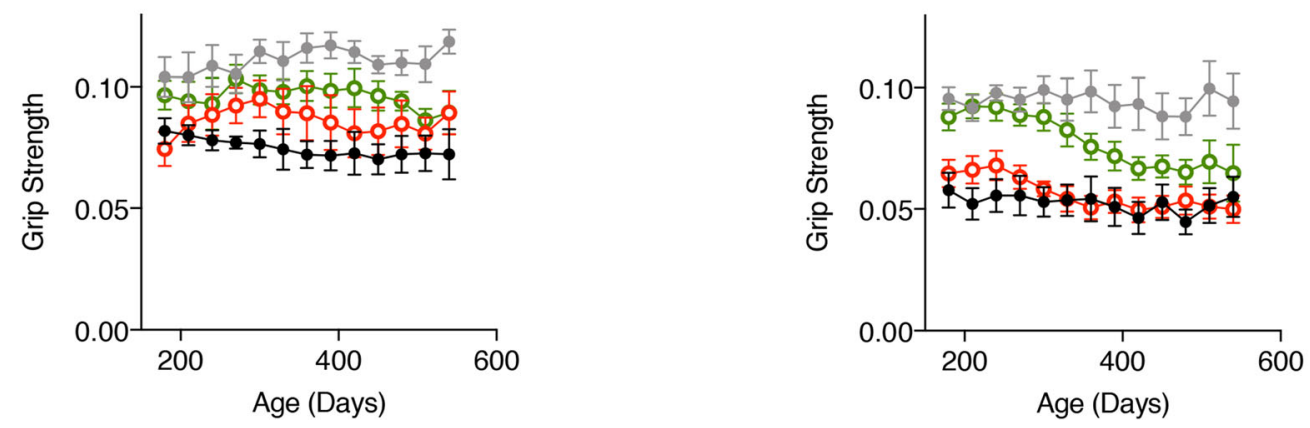

Fig. 1 (See legend on next page.) 
(See figure on previous page.)

Fig. 1 hFUS transgene rescues lethality and motor deficits in Fus ${ }^{\Delta N L S}$ mice. A: Scheme of the breeding strategy. B: Representative genotyping results of 5 mice at 1 month of age. C-D: Kaplan Meier survival curve of the different genotypes either homozygous (C) or heterozygous for the $\triangle N L S$ mutation (D). Note that all FuS ${ }^{\Delta N L S / \Delta N L S}$ mice die at birth, unless carrying a hFUS transgene. ${ }^{*}, p<0.05$ Log Rank test; ${ }^{* * *}, p<0.001$ Log rank test. E: Age-dependent changes in the mean hanging time (s) and holding impulse (Ns) in the four-limb wire inverted grid test in Fus ${ }^{+/+}(+/+)$, and Fus ${ }^{\Delta N L S /+}(\Delta /+)$ mice with or without hFUS transgene. $N=10-28$ per group. Mixed effect analysis, with 3 factors (Age, $\triangle N L S$ genotype and hFUS genotype). $P<0.001$ for $\triangle N L S$ genotype, $P<0.001$ for age, $P<0.001$ for hFUS genotype. A significant protective interaction is observed between $\triangle$ NLS and hFUS genotypes ( $p=0.0216$, and $p=0.0366$ ). Only 4 groups out of 5 are shown here for clarity. The whole dataset is shown in Fig S1. F: Hindlimb grip strength in female and male mice. Mixed effect analysis, with 3 factors (Age, $\triangle N L S$ genotype and hFUS genotype). For female mice, $P<0.001$ for $\triangle N L S$ genotype, $p=n$ for age, $p=$ ns for hFUS genotype. A significant protective interaction is observed between $\triangle$ NLS and hFUS genotypes $(p=0.0131)$. For male mice, $P<0.001$ for $\triangle$ NLS genotype, $p=n$ for age, $p=\mathrm{ns}$ for hFUS genotype. No significant protective interaction is observed between $\triangle \mathrm{NLS}$ and hFUS genotypes $(p=0.0512)$

cytoplasmic fractions. Indeed, and as expected [11, 12], cytoplasmic FUS levels were elevated by five-fold in cerebral cortex of $\mathrm{Fus}^{\mathrm{NLS} /+}$ mice as compared to corresponding wild-type mice (Fig. 2 C-D and Source data for uncropped western blots) demonstrating that this increase is related to the mislocalization of the mutant protein. Importantly, the increase in mouse FUS in cytoplasmic fractions of $\mathrm{Fus}^{\mathrm{\Delta NLS} /+}$ mice, was normalized by the hFUS transgene (Fig. 2 C). Contrastingly, nuclear FUS levels were similar in all genotypes, irrespective of the presence of the Fus ${ }^{\Delta N L S}$ mutation or that of the hFUS transgene. Human FUS levels were increased in $F u s^{\Delta \mathrm{NLS} / \Delta \mathrm{NLS}}$ mice carrying a hFUS transgene, likely compensating for the loss of nuclear FUS of mouse origin. In spinal cord sections, Fus ${ }^{\Delta \mathrm{NLS} /+}$ neurons displayed a mixed cytoplasmic and nuclear FUS staining, that was prevented by the hFUS transgene (Fig. $3 \mathrm{~A}$ ), and this was also observed in motor neurons using an antibody detecting total FUS using double FUS/ChAT immunofluorescence (Fig. 3B). No cytoplasmic staining was observed when using a C-terminal antibody (Fig. $3 \mathrm{C}$ ), further confirming that the cytoplasmic staining is derived from mutant FUS protein. Indeed, specific immunolabelling of mouse FUS showed decreased overall signal in mice with hFUS transgene, and loss of cytoplasmic staining in $\mathrm{Fus}^{\Delta \mathrm{NLS} /+} / \mathrm{hFUS}$ motor neurons (Fig. 3D). Interestingly, we observed significant nuclear staining for mouse FUS in Fus $^{\Delta \mathrm{NLS} / \Delta \mathrm{NLS}} / \mathrm{hFUS}$ motor neurons despite the lack of NLS in mouse FUS in this genotype (Fig. 3D). Accumulation of cytoplasmic asymmetrically dimethylated (ADMA) FUS is a feature of FUS-ALS $[5,6,19]$ patients which was recapitulated in the $\mathrm{Fus}^{\Delta \mathrm{NLS} /+}$ mice, as we previously reported [12]. Here, this significant increase in ADMA-FUS detected in Fus $^{\Delta \mathrm{NLS} /+}$ cytoplasmic fractions, was largely prevented by the hFUS transgene in $\mathrm{Fus}^{\Delta \mathrm{NLS} /+} / \mathrm{hFUS}$ mice (Fig. 3 C-D), but not in $F u s^{\Delta N L S / \Delta N L S} /$ hFUS mice. While ADMA-FUS immunoreactivity was clearly detected in the cytoplasm of $F u{ }^{\Delta \mathrm{NLS} /+}$ motor neurons, expression of the hFUS transgene in $\mathrm{Fus}^{\Delta \mathrm{NLS} /+} / \mathrm{hFUS}$ led to reduced ADMA-FUS immunoreactivity signal in $\mathrm{Fus}^{\Delta \mathrm{NLS} /+}$ mice
(Fig. 3E). It should be noted however, that motor neurons of $F_{u s}{ }^{\Delta N L S / \Delta N L S} /$ hFUS mice still displayed residual amounts of cytoplasmic FUS (Fig. 3B, D, E). These results thus suggest that wild-type hFUS restores aberrant FUS nearly to normal levels but does not completely abolish FUS mislocalization.

\section{Wild-type FUS transgene activates autoregulation of mutant Fus to decrease mutant FUS protein}

Consistent with the results of western blotting, total levels of mRNA encoding FUS (both endogenous mouse and human transgene derived) increased in Fus ${ }^{\Delta \mathrm{NLS} /+}$ spinal cord, and were further elevated by the hFUS transgene in Fus ${ }^{\Delta \mathrm{NLS} /+} / \mathrm{hFUS}$ and Fus ${ }^{\Delta \mathrm{NLS} / \Delta \mathrm{NLS}} / \mathrm{hFUS}$ spinal cord (Fig. 4 A) and frontal cortex (Fig S2). However, levels of endogenous Fus mRNA, that are increased in $\mathrm{Fus}^{\mathrm{N \textrm {NS } / +}}$ mice, were corrected by hFUS transgene in 1-month old spinal cord (Fig. 4B) and frontal cortex (Fig. S2) of $F s^{\Delta \mathrm{NLS} /+} / \mathrm{hFUS}$ and $F u s^{\Delta \mathrm{NLS} / \Delta \mathrm{NLS}} / \mathrm{hFUS}$ animals, leading to accumulated mouse Fus mRNA levels close to those of endogenous Fus in normal nontransgenic mice. This restoration of mouse Fus mRNA levels by hFUS transgene was sustained through aging as observed in 22-month old Fus ${ }^{\Delta \mathrm{NLS} /+} / \mathrm{hFUS}$ mice. Consistently, mutant $F u s^{\triangle N L S}$ mRNA levels decreased in spinal cord and frontal cortex of $\mathrm{Fus}^{\Delta \mathrm{NLS} /+} / \mathrm{hFUS}$ and Fus $^{\Delta \mathrm{NLS} / \Delta \mathrm{NLS}} / \mathrm{hFUS}$ animals compared to the Fus ${ }^{\Delta \mathrm{NLS} /+}$ mice (Fig. 4D and Fig. S2), while human FUS mRNA levels remained comparable across the three genotypes with hFUS transgene (Fig. $4 \mathrm{C}$ and Fig. S2).

We further investigated the three possible autoregulatory mechanisms that have been documented for FUS (Fig. S3). First, FUS protein is proposed to bind to its own pre-mRNA, leading to the splicing of exon 7 , and the possible subsequent degradation of the abnormally $\triangle$ exon 7 FUS mRNA through nonsense-mediated mRNA decay $[15,20]$. Interestingly, expression of hFUS transgene increased levels of the aberrantly spliced Fus $\triangle$ exon 7 mRNA (Fig. 5 A and Fig. S4A). Secondly, increased FUS levels have recently been reported to lead to the retention of introns 6 and 7 in the mature mRNA, 


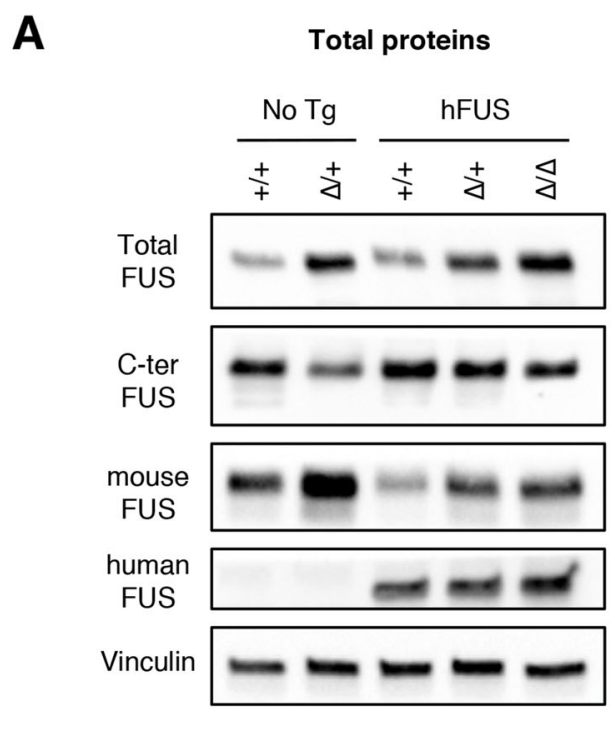

B
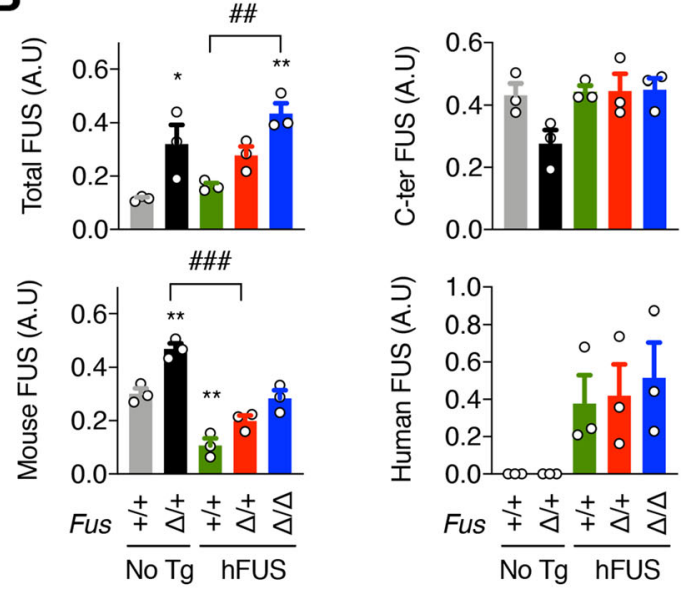

D
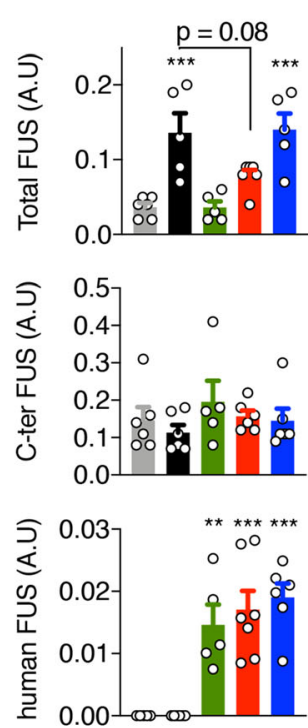
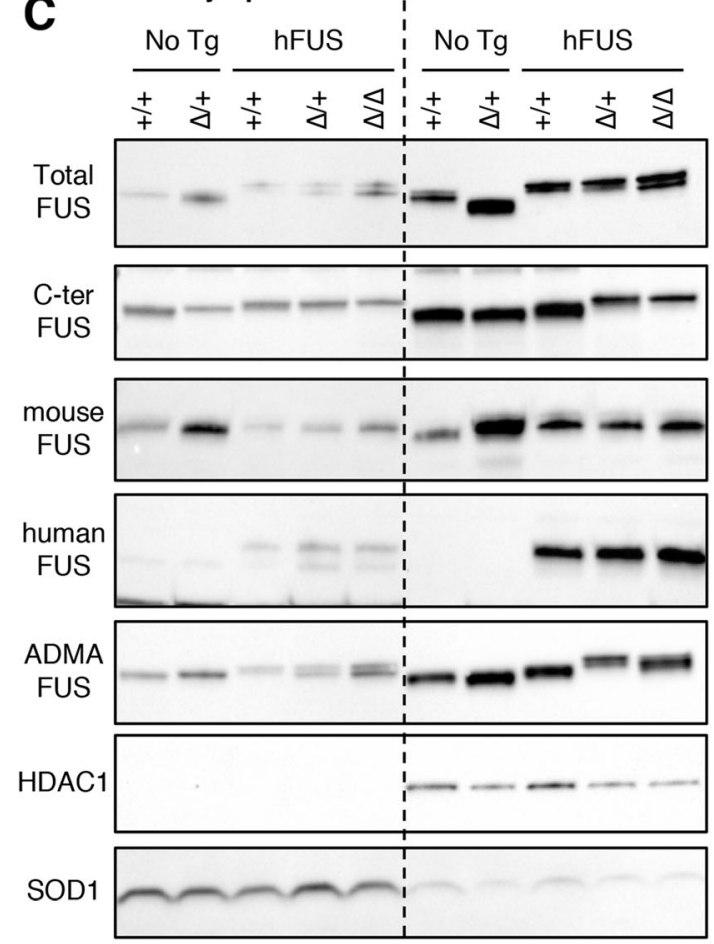

SOD1

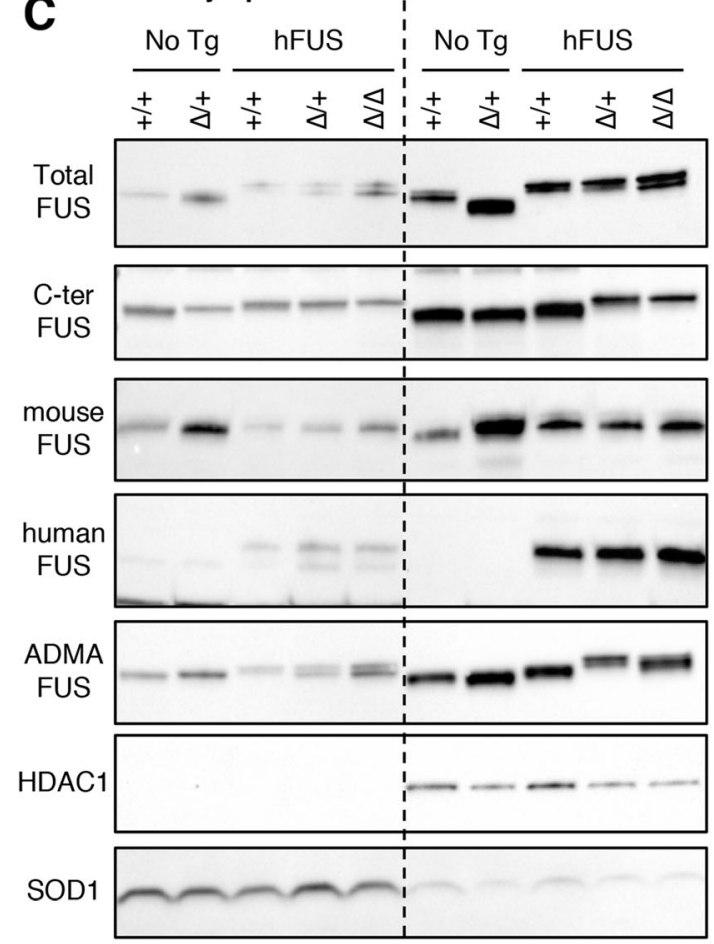

Nucleus

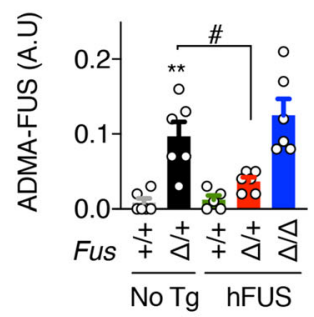

Nucleus
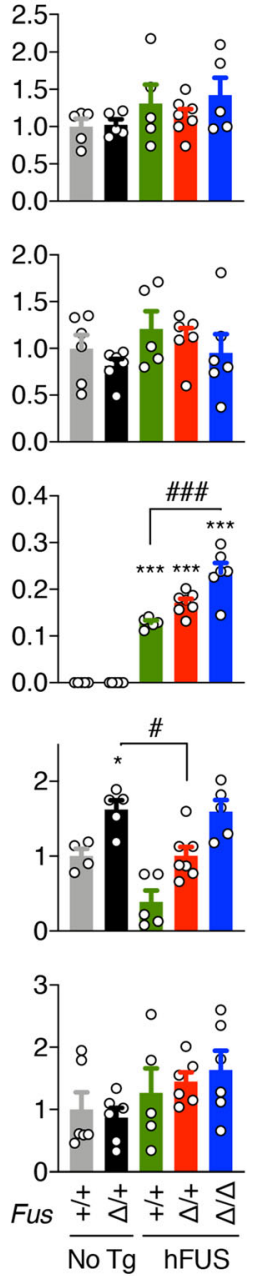

Fig. 2 (See legend on next page.) 
(See figure on previous page.)

Fig. 2 hFUS transgene corrects abnormal levels of FUS protein in Fus ${ }^{\triangle N L S}$ mice. A: Immunoblot analysis of FUS protein in total extracts from Fus $^{+/+}(+/+)$and FUS ${ }^{\Delta N L S /+}(\Delta /+)$ brains with or without hFUS transgene and of FUS ${ }^{\Delta N L S / \triangle N L S}$ mice $(\Delta / \Delta)$ with hFUS transgene at 22 months of age. Representative results using different antibodies revealing total FUS, the C-terminal (C-ter) NLS, mouse FUS, and human FUS. Vinculin was used as loading controls. Note that these immunoblots were performed on different membranes to avoid cross reaction between different antibodies and one representative Vinculin blot is shown. Uncropped western blots and their corresponding Vinculin western blots are provided in Source data. B: Quantification of immunoblotting experiments of panel A. Quantification of total, C-ter, mouse, human and ADMA-FUS protein levels in cytoplasmic and nuclear fractions of the indicated genotypes. $N=4-8 .{ }^{*} p<0.05,{ }^{* * *} p<0.001$ vs Fus ${ }^{++}, \#, p<0.05$ and \#\#\#, $p<0.001$ vs. indicated genotype by ANOVA followed by Tukey. C: Immunoblot analysis of FUS protein subcellular localization in cortex of Fus ${ }^{+/+}(+/+)$and Fus ${ }^{\Delta N L S /+}$ $(\Delta /+)$ mice with or without hFUS transgene and of Fus ${ }^{\Delta N L S / \Delta N L S}$ mice $(\Delta / \Delta)$ with hFUS transgene at 1 month of age. Representative results using different antibodies revealing total FUS, the C-terminal (C-ter) NLS, mouse FUS, human FUS and asymmetrically dimethylated arginine FUS (ADMA-FUS). SOD1 and HDAC1 are used as loading controls for cytoplasmic and nuclear protein extracts fractions, respectively. Note that these immunoblots were performed on different membranes to avoid cross reaction between different antibodies. Uncropped western blots and corresponding stain free gels are provided in Source data. D: Quantification of western blotting experiments of panel C. Quantification of total, Cter, mouse, human and ADMA-FUS protein levels in cytoplasmic and nuclear fractions of the indicated genotypes. $N=4-8 .{ }^{*} p<0.05$, ${ }^{* * *} p<$

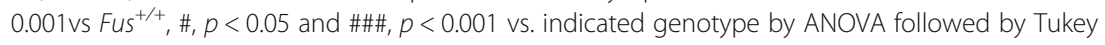

and to the nuclear retention of the aberrant transcripts [14]. Fus endogenous mRNAs with retained introns 6 or 7 strongly increased in all mice expressing hFUS transgene at 1- and 22-months of age (Fig. 5B-C and Fig. S4B-C). We also observed prominent retention of human intron 7 in all samples derived from mice expressing the hFUS transgene (Fig. 5D and Fig S4D), which is consistent with the strong conservation of introns 6 and 7 between species (Fig S5). Thirdly, besides intron skipping and retention, FUS has also been reported to regulate its own levels through the stimulation of miR200
[16]. Another target of miR200 is ZEB1, whose expression is dependent upon levels of miR200 [21, 22]. Here, Zeb1 expression appears unchanged in Fus ${ }^{\Delta \mathrm{NLS} /+}$ tissues, whether or not expressing the hFUS transgene (Fig. S6), indirectly suggesting that this latter autoregulatory mechanism is not engaged in the effects mediated by the hFUS transgene.

To identify the predominant autoregulatory mechanism(s) contributing to reduction of mutant FUS by hFUS, i.e. intron retention and/or exon skipping, we performed RT-PCR using trios of oligonucleotides allowing






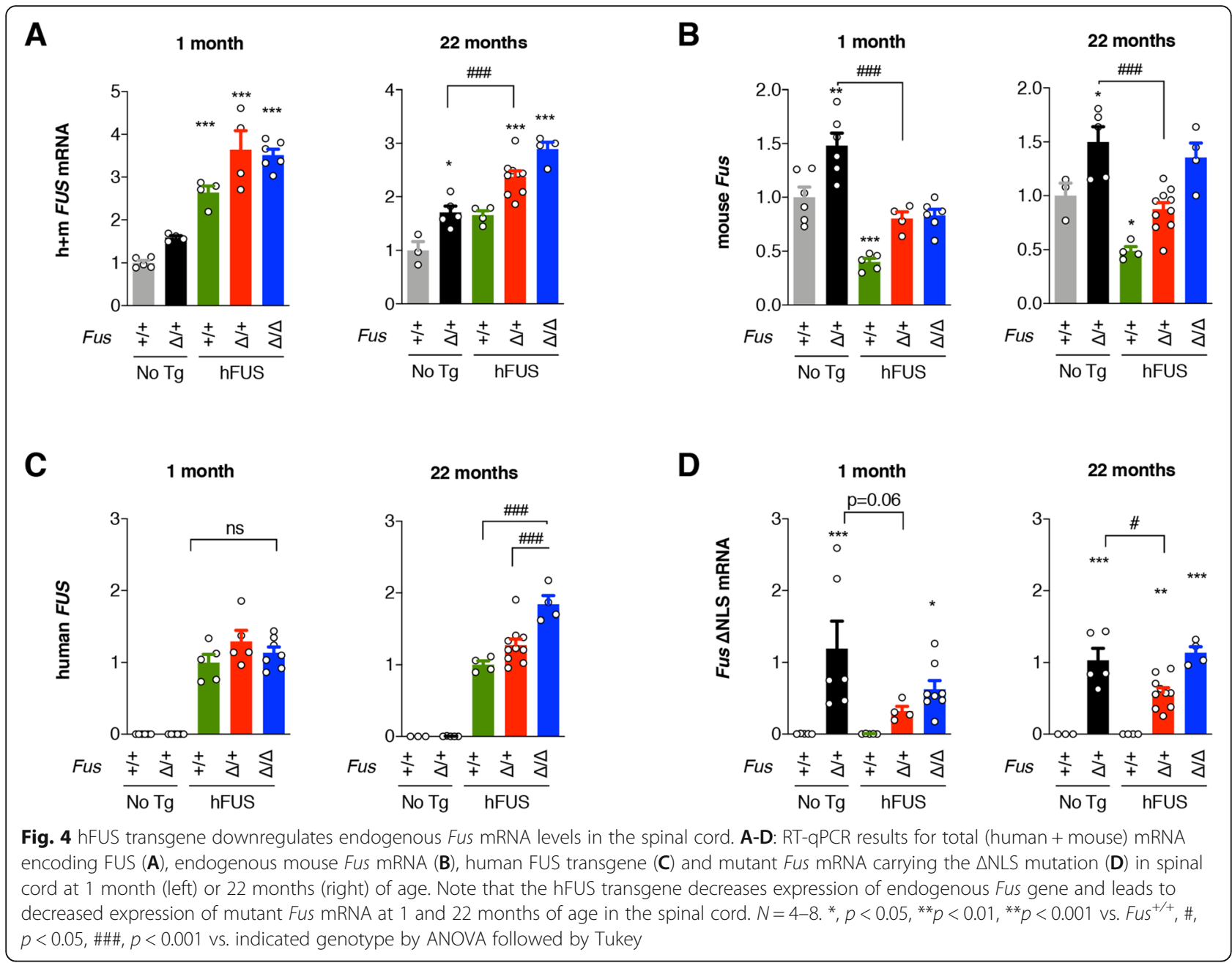

to calculate a percentage of intron retention or exon skipping relative to the total amount of Fus mRNA. As shown in Fig. 5E, and quantitated in Fig. $5 \mathrm{~F}$ and $\mathrm{H}$ (uncropped gels shown in Source data), a significant proportion of mouse Fus mRNA retained either intron 6 or intron 7 in wild-type tissues, and this proportion decreased with the $\triangle \mathrm{NLS}$ transgene, consistent with inhibition of autoregulatory intron retention in these conditions [14]. Conversely, the large majority of mouse Fus mRNA appeared to retain intron 6 or intron 7 in the presence of hFUS transgene (Fig. 5E-H, Fig. S4). In the same conditions, we were unable to detect a significant proportion of $\Delta$ exon 7 mouse mRNA, suggesting that, while this species can be detected using RT-qPCR (Fig. 5E), it is quantitatively minor. Collectively, these data indicate that wild-type human FUS gene decreases expression of the endogenous Fus gene through increased retention of introns 6 and 7 leading to decreased production of toxic FUS ${ }^{\Delta N L S}$ protein, and subsequent alleviation of all the downstream consequences of the expression of cytoplasmically mislocalized mutant FUS.

\section{Discussion}

In the current study, we show that providing a wild-type allele of the FUS gene is sufficient to rescue ALS-like phenotypes associated with cytoplasmically retained mutant FUS protein expression. Our result appears $a$ priori paradoxical since the toxicity of FUS mutations was shown to be largely driven by cytoplasmic FUS [7-12], that is not expected to be directly compensated by the wild-type protein. Furthermore, overexpression of the wild-type protein was shown to be toxic to neurons $[9,17,23]$.

The wild-type FUS transgene rescues phenotypes associated with the Fus ${ }^{\Delta N L S}$ mutation

In this study, the hFUS transgene displayed broad protective effects against the lethality driven by the $F u{ }^{\Delta N L S}$ allele in homozygosity. We previously showed that $F u{ }^{\triangle N L S / \triangle N L S}$ mice die at birth due to an inability to inflate lungs [11]. Here, this perinatal lethality was fully prevented by the hFUS transgene, and numbers of Fus ${ }^{\triangle N L S / \triangle N L S}$ mice expressing the hFUS transgene were 
A

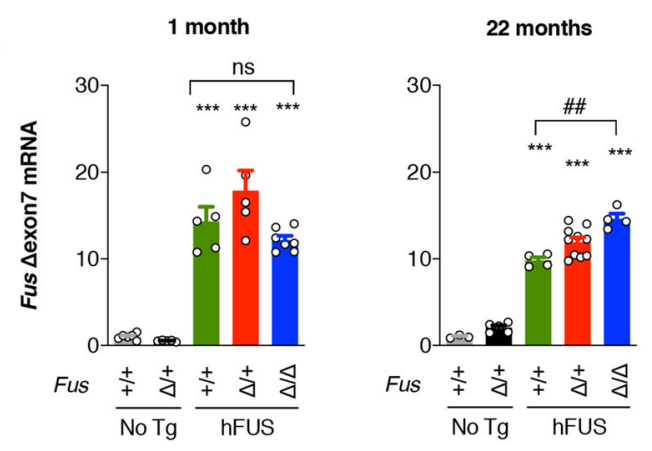

C

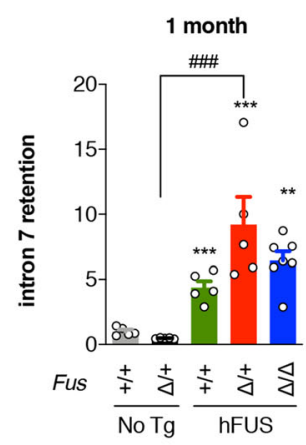

E

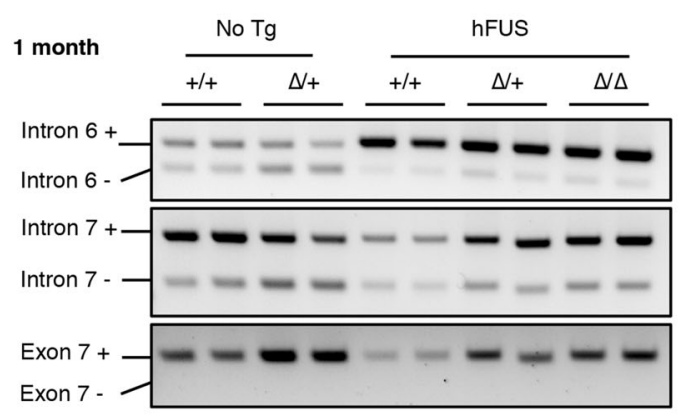

G

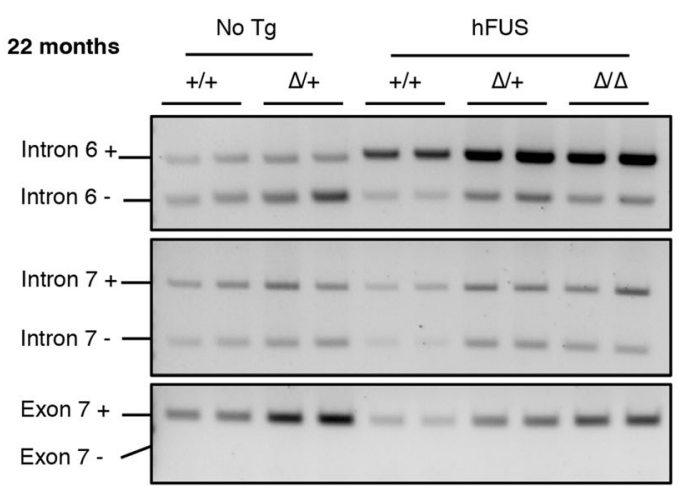

B
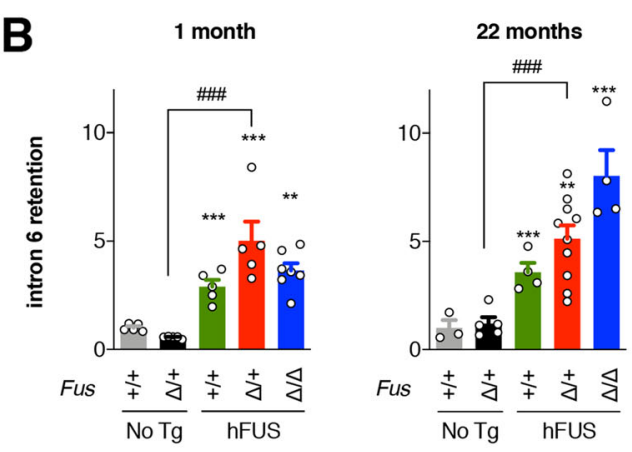

D
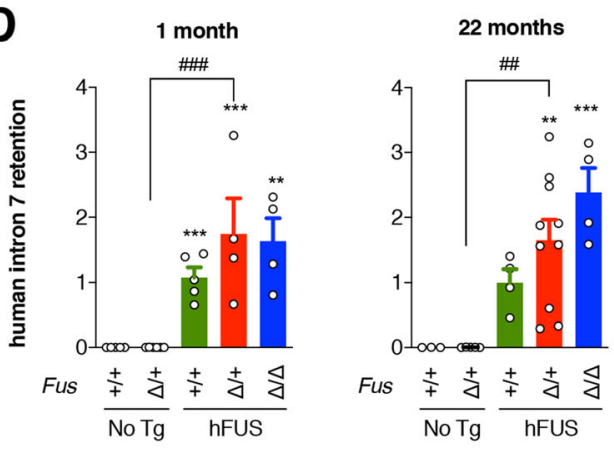

$\mathbf{F}$
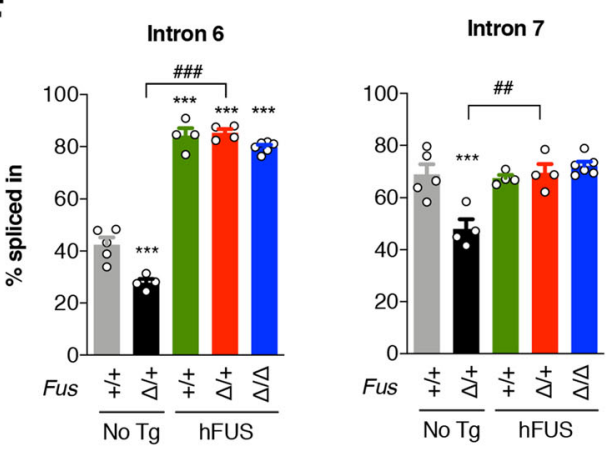

H

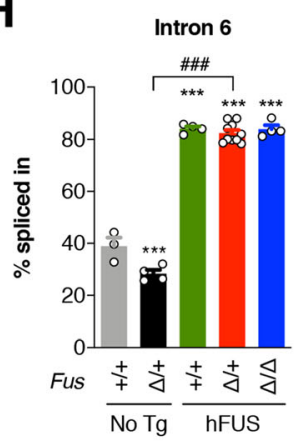

Intron 7

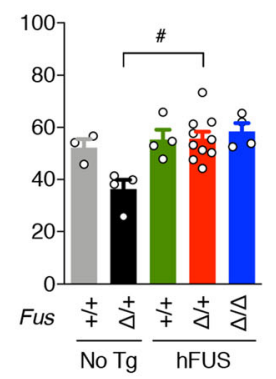

Fig. 5 (See legend on next page.) 
(See figure on previous page.)

Fig. 5 hFUS transgene activates autoregulatory splicing in Fus ${ }^{\Delta N L S /+}$ spinal cord. A-D: RT-qPCR results for endogenous Fus mRNA deleted of exon 7 (A), endogenous Fus mRNA retaining intron 6 (B), endogenous Fus mRNA retaining intron 7 (C) and exogenous FUS mRNA retaining intron 7 (D) in spinal cord at 1 month (left) or 22 months (right) of age. Note that the hFUS transgene activates autoregulatory exon 7 skipping as well as retentions of introns 6 and 7 in endogenous mRNA and retention of intron 7 in exogenous mRNA at 1 and 22 months of age. $N=4-8 .{ }^{*}, p<$ $0.05,{ }^{* *} p<0.01,{ }^{* * *} p<0.001$ vs. Fus ${ }^{+/+}, \#, p<0.05$, \#\#\#, $p<0.001$ vs. indicated genotype by ANOVA followed by Tukey. E-H: representative gel electrophoresis of RT-PCR assays identifying RNA species with or without intron 6 retention $(\mathbf{E}, \mathbf{G}$, upper panel), with or without intron 7 retention $(\mathbf{E}, \mathbf{G}$, middle panel), or with or without exon 7 skipping $(\mathbf{E}, \mathbf{G}$, lower panel) in spinal cord at $1(\mathbf{E})$ or $22(\mathbf{G})$ months of age. We did not detect exon 7 skipped mRNA using these assays. Panels $\mathrm{F}$ and $\mathrm{H}$ show the percentage of intron 6 or 7 retention (intron + band intensity divided by the sum of intensities of intron + and intron - bands, multiplied by 100$)$, for 1 month $(\mathbf{F})$ or 22 months $(\mathbf{H})$ of age. $N=4-8 .{ }^{* * *} p<0.001$ vs. Fus ${ }^{+/+}$, \#, $p<0.05, \# \#, p<0.01, \# \#, p<0.001$ vs. indicated genotype by ANOVA followed by Tukey

obtained at the expected mendelian ratio, consistent with a full rescue. However, and in spite of surviving the perinatal period, a proportion of homozygous rescued mice died prematurely and abruptly at an adult age (about $20 \%$ by one year of age). The only noticeable phenotype observed in these mice was an age-related decrease in body weight gain, but we did not observe prominent weakness, nor obvious ALS-related symptoms. A possible cause of death could be an increased sensitivity to epileptic seizures, as we recently showed that $F u s^{\Delta N L S /+}$ mice display increased spontaneous cortical neuronal activity [18]. Further work on these mice is required to finely characterize their phenotypes and pinpoint to the cause of their premature death.

How can the hFUS transgene rescue the perinatal lethality of $F u s^{\triangle N L S / \triangle N L S}$ mice? Perinatal death of Fus ${ }^{\triangle N L S / \triangle N L S}$ mice is similar to that of mice with a complete ablation of FUS. This suggests that the presence of FUS in the nucleus during development is required to bypass the perinatal period. Thus, it is likely that the hFUS transgene allows for the production of sufficient functional nuclear FUS to overcome the perinatal lethality of $F u s^{\triangle N L S / \triangle N L S}$ mice. Unexpectedly, a significant fraction of the mouse FUS protein was found in the nucleus of adult Fus ${ }^{\Delta N L S / \triangle N L S}$ mice with hFUS transgene, albeit the endogenous FUS protein is completely truncated of the NLS. This is a priori surprising as the NLS is the major domain responsible for interaction with nuclear import receptors such as karyopherin $ß 2[24,25]$. There are at least two possible explanations to this observation. First, the human FUS protein could support the nuclear import of the mutant $\triangle$ NLS mouse protein as wild-type and mutant FUS interact with each other [26]. Second, nuclear import of FUS might be possible through NLS-independent mechanisms. Indeed, recent work has shown that $\triangle \mathrm{NLS}$ mutants of FUS could still interact through RGG domains with karyopherin $ß 2[24,25]$, as well as other nuclear import receptors [25] leading to significant nuclear import [24] .

Consistent with the protection offered in homozygous mice, the hFUS transgene prevented premature death and muscle weakness in Fus ${ }^{\Delta N L S /+}$ mice. Importantly, the hFUS transgene had no effect per se on survival of wild-type mice. About $30 \%$ of $\mathrm{Fus}^{\Delta N L S /+}$ mice died before 2 years of age, which is consistent with previous findings reported in another knock-in model of FUSALS [10]. Further confirming the protection offered by the hFUS transgene, the motor defect of Fus ${ }^{\Delta N L S /+}$ mice was also rescued. It should be noted however that the expression of the transgene led to mild motor defects, mostly in males in one of the tests (grip strength) used. This suggests that the protection offered by the hFUS transgene might be accompanied with toxicity appearing with age, echoing a recent report on the toxicity of viral overexpression of SMN in spinal muscular atrophy mice [27]. In all, our results demonstrate broad protective effects of the hFUS transgene on the deleterious phenotypes associated with either homozygous or heterozygous Fus ${ }^{\Delta N L S}$ mutation, yet not excluding some residual toxicity associated with the transgene expression.

\section{The wild-type hFUS transgene mitigates disease through autoregulatory mechanisms}

Importantly our work demonstrates that the wild-type transgene activates FUS autoregulatory loop to mitigate the phenotype. A first possible protective mechanism could have been that the hFUS transgene rescues a loss of nuclear FUS. However, we did not observe any loss of nuclear FUS in $\mathrm{Fus}^{\Delta N L S /+}$ mice. Alternatively, the hFUS transgene appears to indirectly protect from accumulation of mutant protein through the autoregulatory loop maintaining nuclear FUS levels $[14,15,20]$ to avoid the toxicity of loss of nuclear FUS [28-32] or its excess $[9,17,23]$. We provide several lines of evidence demonstrating the engagement of FUS autoregulation upon expression of the hFUS transgene. First, Fus mRNA and protein levels are increased in Fus ${ }^{\Delta N L S /+}$ mice, thereby compensating the proportion of FUS protein translated from the mutant allele and unable to enter the nucleus. Conversely, in single hFUS transgenic mice the addition of the exogenous FUS transgene is sufficient to decrease endogenous mouse Fus mRNA levels, consistent with previous studies [8, 9]. Here, the addition of the hFUS transgene in $\mathrm{Fus}^{\Delta N L S /+}$ mice rescued overexpression of endogenous Fus in Fus ${ }^{\Delta N L S /+}$ mice, 
and decreased mutant mRNA levels. Since this overexpression acts as a feed forward mechanism amplifying the cytoplasmic accumulation of FUS, avoiding this overexpression might on its own be sufficient to slow down the vicious cycle leading to phenotypes in $\mathrm{Fus}^{\Delta N L S /+}$ mice. Consistently, our RT-PCR experiments demonstrate that a significant proportion of Fus mRNA retains introns 6 and 7, and that the percentages of intron retention in the endogenous Fus mRNA increase strikingly with the expression of the hFUS transgene. Importantly, the exogenous human transgene is also, on its own, subject to autoregulation in $F u s^{\Delta N L S /+}$ mice, despite the heterologous system. This is consistent with the strikingly high conservation of introns 6 and 7 of the FUS gene between species suggesting that autoregulation of FUS is critical for its functions (Fig. S5). Of note, the existence of autoregulation of the human transgene in the mouse model is a plausible explanation for the high toxicity of cDNA-based constructs devoid of required autoregulatory sequences, and the relative innocuity of genomic based constructs $[8,9,17]$.

Our findings are in agreement with previous studies identifying retention of introns 6 and/or 7 as the major mechanism of Fus autoregulation [14]. Indeed, about half of the endogenous Fus transcript appears retaining either intron 6 or 7 in the cortex or spinal cord of wildtype mice. Consistent with the results of Humphrey and collaborators, the $\triangle \mathrm{NLS}$ mutation leads to decreased retention of these two introns in both tissues. On the contrary, the introduction of the hFUS transgene leads to substantial retention of both introns, with nearly $90 \%$ of endogenous Fus mRNA having intron 6 retained. The effect of the hFUS transgene appeared less marked on retention of intron 7 , albeit this intron carries most of the FUS binding sites on the pre-mRNA $[14,15,20]$. In addition to the substantially increased intron retention upon hFUS transgene expression, we also observed enhanced exon 7 skipping. This mRNA species appeared however minor, as it was not observed using splicing assays, and required 4-6 supplementary PCR cycles to be detectable. While this suggests that exon skipping is a minor mechanism of FUS autoregulation in our in vivo model, our current results do not allow to completely exclude its contribution as Zhou and collaborators demonstrated that $\triangle$ exon 7 Fus mRNA is subject to nonsense mediated mRNA decay (NMD) [15]. Nevertheless, other studies suggest that NMD is not involved in FUS autoregulation, at least in cultured cells [14]. Further, our study did not find evidence of altered miR141/200/ ZEB1 pathway [16] by measuring Zeb1 mRNA levels. Thus additional work is needed to fully evaluate the contribution of this pathway to in vivo FUS autoregulation. In all, our efforts are consistent with a predominant role of intron retention in FUS autoregulation in vivo, and further research is warranted to identify which intron is critical for this process.

Possible consequences for therapeutic strategies in FUS-ALS Our results suggest that gene therapy to reintroduce the wild-type protein, while including sequences required for autoregulation, would enable the correction of molecular and behavioral phenotypes, meanwhile avoiding the toxicity of wild-type protein overexpression in FUSALS. Our work provides a proof of concept for a potential therapeutic strategy, albeit there are limitations to overcome before clinical translation. First, our study has been obtained in a heterologous system, with a human FUS transgene expressed in mouse cells. While the very high conservation of intronic sequences (Fig S5) gives hopes that a similar intervention should be protective also in human cells, an intermediate validation step using a human cell model is warranted. Second, our current results have been obtained using a complete FUS gene inserted through classical transgenesis in a locus independent of the mouse Fus gene. To translate these results in a therapeutically viable strategy, it would be first necessary to use a gene therapy vector, such as an adeno-associated virus (AAV), to provide the equivalent of our hFUS transgene. Thus, an important effort of sequence optimization is required to shorten the lead "therapeutic" construct, in order to allow introduction of a potential therapeutic sequence into the viral vector. Future research should thus aim at identifying the minimal sequence requirements for FUS autoregulation to ultimately engineer a small autoregulation competent expression construct.

Besides FUS-ALS, FUS mutations have been associated with other neurodegenerative diseases, such as frontotemporal dementia [33-35], chorea [36], mental retardation [37], psychosis [38] and essential tremor [39]. FUS aggregation has been observed in sporadic ALS [40-42] and FTD [43-45], but also in spino-cerebellar ataxia and Huntington's disease [46, 47]. A gene therapy to restore normal nuclear FUS levels might thus be relevant for other patients to be identified. Last, it is noteworthy that similar autoregulatory mechanisms exist for other RNAbinding proteins, in particular TDP-43 [48-53] or hnRNPA1 [54]. Whether utilizing such autoregulatory mechanisms to decrease mutant protein through overexpression of a wild-type protein might be a general therapeutic approach in such diseases remains to be determined.

\section{Conclusions}

Our results show that the phenotypes triggered by a cytoplasmically retained FUS protein associated to ALS can be rescued by a wild type FUS allele. The wild-type FUS allele activates the homeostatic autoregulatory loop 
triggering retention of introns 6 and 7 in the endogenous Fus mRNA, leading to decreased mutant protein load. Our work provides a proof of concept for a potential gene therapy strategy for FUS-ALS.

\section{Materials and methods}

\section{Mouse models and genotyping}

Mouse experiments were approved by local ethical committee from Strasbourg University (CREMEAS) under reference number 2,016,111,716,439,395 and all experimental procedures performed in San Diego were approved by the Institutional Animal Care and Use Committee of the University of California, San Diego. Transgenic mice were generated as described in [11, 12] and [8], were bred in Charles River animal facility and housed in the Faculty of medicine from Strasbourg University with 12/12 hours of light/dark cycle (light on at 7:00 am) under constant conditions $\left(21 \pm 1{ }^{\circ} \mathrm{C}\right.$; $60 \%$ humidity) and with unrestricted access to food and water.

Mice were weaned and genotyped at 21 days by PCR from tail biopsy, or at death if occurring before 21 days of age.

The following primer sequences were used to genotype mice:

hFUS-For: GAATTCGTGGACCAGGAAGGTC.

hFUS-Rev: CACGTGTGAACTCACCGGAGTCA.

FUS-For: GAT-TTG-AAG-TGG-GTA-GAT-AGT-GCA-GG. FUS-Rev: CCT-TTC-CAC-ACT-TTA-GTT-TAG-TCA-CAG.

Heterozygous Fus $^{\Delta \mathrm{NLS} /+}$ knock-in mice, lacking the PY-NLS, were crossed with mice expressing human wild type FUS from a complete, autoregulatory competent, human gene to obtain following genotypes: $\mathrm{Fus}^{+/+}$, $\mathrm{Fus}^{\Delta N L S /+} \mathrm{Fus}^{\Delta N L S / \Delta \mathrm{NLS}}, \mathrm{Fus}^{+/+} / \mathrm{hFUS}, \mathrm{Fus}^{\Delta \mathrm{NLS} /+} / \mathrm{hFUS}$, $F{ }^{\Delta N L S / \Delta N L S} /$ hFUS. The genetic background of all mice used in this study is C57Bl6/J. Breeding steps were performed in parallel in both laboratories. 76 mice of the F2 generation were generated in Strasbourg, and 110 mice of the F2 generation were generated in San Diego.

\section{Mouse behavior Survival}

Survival was studied during the first hours after birth and dead new born mice were genotyped. Mice surviving the post-natal period were genotyped at 21 days and followed weekly until death or euthanized using ketamine-xylazine when they reach the following endpoints: auto-mutilation, weight loss greater than $10 \%$ of the initial weight and when they could not turn around again within $10 \mathrm{~s}$ after being laid on their side.

\section{Inverted grid}

Mice were habituated for $30 \mathrm{~min}$ in the test room prior testing. Motor performance was assessed weekly as described previously [12] from 1 month until 22 months of age. The wire grid hanging time (or "hang time") was defined as the amount of time that it takes the mouse to fall down from the inverted grid and was measured visually with a stopwatch. The procedure was repeated 3 times during 5 min with 5 min break between tests. All mice were returned to their homecage after completing the test. The holding impulse corresponds to hanging time normalized with mouse weight and gravitational force.

\section{Grip test}

Grip strength was measured using a Grip Strength Meter (Columbus Instruments, Columbus, $\mathrm{OH}$ ) on $\mathrm{co}^{-}$ horts $(\mathrm{N}=12-30)$ made up of approximately the same number of males and females. Mice were allowed to grip a triangular bar only with hind limbs, followed by pulling the mice until they released; five force measurements were recorded in each separate trial.

\section{Histological techniques}

Mice aged of 22 months were anesthetized with intraperitoneal injection of $100 \mathrm{mg} / \mathrm{kg}$ ketamine chlorhydrate and $5 \mathrm{mg} / \mathrm{kg}$ xylazine then perfused with PFA $4 \%$. After dissection, spinal cord was included in agar $4 \%$ and serial cuts of $40 \mu \mathrm{m}$ thick were made with vibratome.

\section{Peroxidase immunohistochemistry}

For peroxidase immunohistochemistry, sections were incubated 10 min with $\mathrm{H}_{2} \mathrm{O}_{2} 3 \%$, washed 3 times and blocked with $8 \%$ Horse serum, 0,3\% Bovine Serum Albumin and 0,3\% Triton in PBS with 0,02\% Thimerosal. Sections were incubated with rabbit anti-FUS antibody (ProteinTech 11570-1-AP; diluted 1:100) in blocking solution overnight at room temperature. After washing sections, they were incubated for $2 \mathrm{~h}$ at room temperature with biotinylated donkey anti-rabbit antibody (Jackson 711-067-003; diluted 1:500) in blocking solution. Then, sections were washed, incubated for $1 \mathrm{~h}$ in horseradish peroxidase $A B C$ kit (Vectastain $A B C$ kit, PK-6100, Vector Laboratories Inc.), washed and incubated with DAB (Sigma, D5905). The enzymatic reaction was stopped by adding PBS $1 \mathrm{X}$ and washed with water. Finally, sections were mounted with DPX mounting medium (Sigma, O6522).

\section{Immunofluorescence}

After epitope retrieval in $10 \mathrm{mM}$ citrate pH6.0 $30 \mathrm{~min}$ at $80{ }^{\circ} \mathrm{C}$, sections were incubated in blocking solution $(5 \%$ Horse serum, $1 \%$ Triton in PBS) at room temperature for $30 \mathrm{~min}$, then incubated overnight at room temperature in primary antibody in PBS $+0.1 \%$ triton X100: rabbit anti-FUS antibody (total FUS) (ProteinTech, 11570-1-AP, 1:100), Rabbit anti-C-ter FUS (Bethyl, A300-294 A, 1/100), Rabbit anti-mouse FUS[8], goat 
anti-ChAT (Millipore, AB144P, 1/50), rat anti-ADMA FUS $([5,6]$, kind gift of Pr C. Haass, Munich Germany, 1/20). After 3 rinses in PBS, sections were incubated for $2 \mathrm{~h}$ at room temperature with Hoechst (Sigma, B2261, $1 / 50.000)$ and secondary antibodies in blocking solution: Alexa-488-conjugated donkey anti-rabbit secondary antibody (Jackson, 711-547-003, 1/500) Alexa-488conjugated donkey anti-rat secondary antibody (Jackson 712-545-153 1/1000) or Alexa-594-conjugated donkey anti-goat secondary antibody (Molecular Probes, A $11,058,1 / 500)$. Finally, sections were subsequently washed with $\mathrm{PBS} 1 \times(3 \times 10 \mathrm{~min})$ and mounted in Aqua/polymount (Polysciences 18,606).

Immunofluorescence staining was monitored with a laser scanning microscope (confocal LSM 800 Zeiss) equipped with $40 \times$ oil objective (NA1.4). Excitation rays are sequential argon laser $488 \mathrm{~nm}$, diode $561 \mathrm{~nm}$, diode $405 \mathrm{~nm}$. Emission bandwidths are $500-570 \mathrm{~nm}$ for Alexa488, 570-617nm for Alexa594, and 400-500nm for Hoechst. Single-layer images were analyzed using ImageJ freeware (http://rsbweb.nih.gov/ij/).

\section{Tissue homogenization, fractionation and western blotting}

Total protein extracts were obtained from brain homogenization using zirconium oxide beads (Bertin Technologies) in combination with Precellys Tissue homogenizer (Bertin Technologies) for $3 \times 15 \mathrm{~s}, 5000 \mathrm{rpm}$ in RIPA buffer (Tris- $\mathrm{HCl} \mathrm{pH} 850 \mathrm{mM}$, sodium chloride $150 \mathrm{mM}$, sodium deoxycholate $0.5 \%$, SDS $0.1 \%$, TritonX100 1\%). The supernatants were collected after centrifugation for $15 \mathrm{~min}, 14,000 \mathrm{rpm}$ at $4{ }^{\circ} \mathrm{C}$ and the protein extracts were measured with Pierce ${ }^{\mathrm{rix}}$ BCA Protein Assay Kit (Thermo Scientific). SDS-PAGE was performed with $10 \mu \mathrm{g}$ of total protein extracts using Mini-PROTEAN TGX gel 4-15\% (Biorad). Proteins were blotted on PVDF membrane using Mini Trans-Blot ${ }^{\circ}$ Cell (Biorad) and blocked with $10 \%$ non-fat milk during $1 \mathrm{~h}$. Primary antibodies (Rabbit anti-hFUS (1/2000), Rabbit anti-mFUS (1/ 4000), Rabbit anti-FUS (total FUS) (Bethyl, A-300-293 A, 1/2000), Rabbit anti-C-ter FUS (Bethyl, A300-294 A, 1/ 2000), Mouse-anti-vinculin (Merk Millipore, V9131, 1/ 2000)) were incubated overnight at $4{ }^{\circ} \mathrm{C}$ in $3 \%$ non-fat milk. Washing was proceeded with washing buffer (Tris $\mathrm{pH} 7.41 \mathrm{M}, \mathrm{NaCl} 5 \mathrm{M}$, Tween $200.1 \%$ ) and secondary antibodies (anti-rabbit HRP (Agilent, P0448, 1/5000), antimouse HRP (Jackson Immunoresearch, 715-035-150, 1/ 5000) were incubated $1 \mathrm{~h} 30$ at room temperature. After successive washes, proteins were visualized with chemiluminescence using SuperSignal ${ }^{\text {tm }}$ West Pico PLUS Chemiluminescent Substrate (Thermo Scientific, 34,577) and chemiluminescence detector.

Tissues were washed in PBS1x and lysed in NE-PER Nuclear and Cytoplasmic Extraction (Thermo Scientific,
$78,835)$ according to the manufacturer's instructions. Protein extracts were dosed by BCA Assay (Interchim, UP95424A, UP95425A). Thereafter proteins were denatured and SDS page was performed with $30 \mu \mathrm{g}$ of cytoplasmic proteins and $10 \mu \mathrm{g}$ of nuclear proteins on criterion TGX stain free gel 4-20\% (Biorad, 5,678,094). Proteins were blotted on nitrocellulose membrane using semi-dry Transblot Turbo system (BioRad, France) and blocked with $10 \%$ non-fat milk during $1 \mathrm{~h}$. Primary antibodies (Rabbit anti-hFUS ([8, 9], \#14,080, 1/2000), Rabbit anti-mFUS ([8, 9], \#14,082, 1/4000), Rat anti-FUS ADMA ([5, 6], kind gift of Pr C. Haass, Munich Germany, 1/500), Rabbit anti-FUS (total FUS) (Bethyl, A-300-293 A, 1/2000), Rabbit anti-C-ter FUS (Bethyl, A300-294 A, 1/2000), Sheep anti-SOD1 (Calbiochem, 574,597, 1/1000), Rabbit anti-HDAC1 (Bethyl, A300$713 \mathrm{~A}, 1 / 1000)$ ) were incubated overnight at $4{ }^{\circ} \mathrm{C}$ in $3 \%$ non-fat milk. Washing was proceeded with washing buffer (Tris pH 7.4 $1 \mathrm{M}, \mathrm{NaCl} 5 \mathrm{M}$, Tween $20100 \%$ ) and secondary antibodies (anti-rabbit HRP (PARIS, BI2407,1/5000), anti-sheep HRP (Jackson, 713-035-147, 1/5000)) were incubated $1 \mathrm{~h} 30$ at room temperature. After successive washes, proteins were visualized with chemiluminescence using ECL Lumina Forte (Millipore, France) and chemiluminescence detector (Bio-Rad, France). Total proteins were detected with stain free gel capacity (Biorad, 5,678,094) and used to normalize for protein loading. All values were normalized against nuclear levels of FUS in $\mathrm{Fus}^{+/+}$extracts set to 1.

\section{RNA extraction and RT-qPCR}

Total RNA was extracted from spinal cord and frontal cortex using TRIzol $^{\circ}$ reagent (Life Technologies). $1 \mu \mathrm{g}$ of RNA was reverse transcribed with iScript ${ }^{\text {tm }}$ reverse transcription (Biorad, 1,708,841). Quantitative polymerase chain reaction was performed using Sso Advanced Universal SYBR Green Supermix (Bio-Rad 1,725,274) and quantified with Bio-Rad software. Gene expression was normalized by calculating a normalization factor using actin, TBP and pol2 genes according to GeNorm software [55].

Primer sequences are provided in Table S1.

\section{RT-PCR}

$1 \mu \mathrm{g}$ of RNA was reverse transcribed with iScript ${ }^{\mathrm{im}}$ reverse transcription (Biorad, 1,708,841). Polymerase chain reaction was performed using in $25 \mu \mathrm{L}$ microtubes with MasterMix Taq DNApolymerase (VWR International, Ref. 733-1320) using the following programs: Intron 6 retention and exon 7 skipping $\left(5 \mathrm{~min} 95^{\circ} \mathrm{C},\left(30 \mathrm{~s} 95^{\circ} \mathrm{C}\right.\right.$, 30 s $56{ }^{\circ} \mathrm{C}, 30$ s $\left.68{ }^{\circ} \mathrm{C}\right) \times 30 ; 5$ min $68^{\circ} \mathrm{C}$ ), Intron 7 retention $\left(5 \min 95{ }^{\circ} \mathrm{C},\left(30 \mathrm{~s} 95{ }^{\circ} \mathrm{C}, 30\right.\right.$ s $61{ }^{\circ} \mathrm{C}, 30$ s $\left.68{ }^{\circ} \mathrm{C}\right) \mathrm{x}$ 30; $\left.5 \mathrm{~min} 68^{\circ} \mathrm{C}\right), 10 \mu \mathrm{L}$ of the PCR products were loaded on a $2 \%$ agarose (Euromedex, Ref.D5-E) gel electrophoresis with Low Molecular Weight DNA Ladder (NEB, 
Ref. N3233L) and stained with ethidium bromide using standard procedures. For quantification, we quantified individually the signal intensities of the two bands, and computed a \% of intron retention as such: (intensity of Intron + band )/ (intensity of Intron + band + intensity of Intron- band)*100. We did not quantify a percentage of exon 7 skipping as the exon 7 skipped product was below the detection threshold of the assay.

\section{Statistics}

All results from analysis are presented as mean \pm standard error of the mean (SEM) and differences were considered significant when $\mathrm{p}<0.05$. Significance is presented as follows: ${ }^{*} p<0.05,{ }^{* * *} p<0.01$, and ${ }^{* * * *} p<$ 0.001 . For comparison of two groups, two-tailed unpaired Student's $\mathrm{t}$-test was used in combination with Ftest to confirm that the variances between groups were not significantly different. For longitudinal analysis of behavioral data, results were analyzed using a mixed effect analysis with three factors ( $\triangle \mathrm{NLS}$ genotype, hFUS genotype and age) as indicated in the figure legends. Data were analyzed by using the GraphPad Prism version 8.0.

\begin{abstract}
Abbreviations
ADMA: Asymmetrically dimethylated arginine; ALS: Amyotrophic lateral sclerosis; BAC: Bacterial artificial chromosome; CHAT: Choline acetyl transferase; FTD: Fronto-temporal dementia; FUS: Fused in sarcoma; hnRNPA1: Heterogeneous ribonucleoprotein particle A1; NLS: Nuclear localization sequence; TDP-43: TAR DNA binding protein of $43 \mathrm{kDa}$
\end{abstract}

\section{Supplementary Information}

The online version contains supplementary material available at https://doi. org/10.1186/s13024-021-00477-w.

\section{Additional file 1. \\ Additional file 2. \\ Additional file 3 .}

\section{Acknowledgements}

We thank Pr Christian HAASS for the kind gift of the anti-ADMA FUS antibody. Image acquisition and image analysis were performed on the Imaging Platform of the CRBS, PIC-STRA UMS 38, Inserm, Université de Strasbourg and the Plateforme Imagerie In Vitro de Strasbourg.

\section{Author contributions}

ISR, NGP, MMD, SD, SM, SDG, GP, DP, QZ, BM, CZL performed research. DWC, $C L T, S D C$ and LD conceived research. SDC and LD supervised research. ISR, SDC and LD drafted figures and manuscript. All authors read and approved the final manuscript.

\section{Funding}

This work was funded by Agence Nationale de la Recherche (ANR-16-CE920031 to LD, ANR-16-CE16-0015, ANR-19-CE17-0016), by Fondation pour la recherche médicale (FRM, DEQ20180339179 and post-doctoral position to SM), Axa Research Funds (rare diseases award 2019, to LD), Fondation Thierry Latran (HypmotALS, to LD), MNDA (Dupuis/Apr16/852 - 791 to LD), ALSA (2235, 3209 and 8075 to LD and CLT), Association Francaise de Recherche sur la sclérose latérale amyotrophique (2016, to LD; 2021 to LD), AFM Téléthon (Grant \#23646), Target ALS (to CLT), the NINDS/NIH R01-NS108769 (to
CLT), and Muscular Dystrophy Association (to SDC). DP is an FWO postdoctoral fellow. LD is USIAS fellow 2019. CLT is the recipient of the Araminta Broch-Healey Endowed Chair in ALS. ISR was funded by the Région Grand Est (France).

\section{Availability of data and materials}

Data and material are available upon reasonable request to corresponding authors;

\section{Declarations}

\section{Ethics approval}

Mouse experiments were approved by local ethical committee from Strasbourg University (CREMEAS) under reference number 2016111716439395 and all experimental procedures performed in San Diego were approved by the Institutional Animal Care and Use Committee of the University of California, San Diego.

\section{Competing interests}

ISR, GP and LD filed a European patent application partially based on results included in this study.

\section{Author details}

${ }^{1}$ Mécanismes centraux et périphériques de la neurodégénérescence, Centre de Recherches en Biomédecine, Université de Strasbourg, Inserm, UMR-S1118, Strasbourg, France. 'Ludwig Institute for Cancer Research, University of California at San Diego, La Jolla, USA. ${ }^{3}$ VIB-KU Leuven Center for Brain and Disease Research, Department of Neurosciences, KU Leuven, Leuven, Belgium. ${ }^{4}$ Department of Neurology, Massachusetts General Hospital, The Sean M. Healey and AMG Center for ALS at Mass General, Harvard Medical School, Boston, MA, USA. ${ }^{5}$ Broad Institute of Harvard University and MIT, Cambridge, MA, USA.

Received: 11 May 2021 Accepted: 28 July 2021

Published online: 06 September 2021

\section{References}

1. van Es MA, Hardiman O, Chio A, Al-Chalabi A, Pasterkamp RJ, Veldink JH, et al. Amyotrophic lateral sclerosis. Lancet. 2017:390(10107):2084-98.

2. Brown RH Jr, Al-Chalabi A. Amyotrophic Lateral Sclerosis. N Engl J Med. 2017;377(2):162-72.

3. Waibel S, Neumann M, Rabe M, Meyer T, Ludolph AC. Novel missense and truncating mutations in FUS/TLS in familial ALS. Neurology. 2010; 75(9):815-7.

4. Waibel $\mathrm{S}$, Neumann M, Rosenbohm A, Birve A, Volk AE, Weishaupt JH, et al. Truncating mutations in FUS/TLS give rise to a more aggressive ALSphenotype than missense mutations: a clinico-genetic study in Germany. Eur J Neurol. 2013;20(3):540-6.

5. Dormann D, Madl T, Valori CF, Bentmann E, Tahirovic S, Abou-Ajram C, et al. Arginine methylation next to the PY-NLS modulates Transportin binding and nuclear import of FUS. EMBO J. 2012;31(22):4258-75.

6. Suarez-Calvet M, Neumann M, Arzberger T, Abou-Ajram C, Funk E, Hartmann $\mathrm{H}$, et al. Monomethylated and unmethylated FUS exhibit increased binding to Transportin and distinguish FTLD-FUS from ALS-FUS. Acta Neuropathol. 2016;131(4):587-604.

7. Sun S, Ling SC, Qiu J, Albuquerque CP, Zhou Y, Tokunaga S, et al. ALScausative mutations in FUS/TLS confer gain and loss of function by altered association with SMN and U1-snRNP. Nat Commun. 2015;6:6171.

8. Lopez-Erauskin J, Tadokoro T, Baughn MW, Myers B, McAlonis-Downes M, Chillon-Marinas C, et al. ALS/FTD-Linked Mutation in FUS Suppresses Intraaxonal Protein Synthesis and Drives Disease Without Nuclear Loss-ofFunction of FUS. Neuron. 2018;100(4):816-30. e7.

9. Ling SC, Dastidar SG, Tokunaga S, Ho WY, Lim K, llieva H, et al. Overriding FUS autoregulation in mice triggers gain-of-toxic dysfunctions in RNA metabolism and autophagy-lysosome axis. eLife. 2019;8:e40811.

10. Devoy A, Kalmar B, Stewart M, Park H, Burke B, Noy SJ, et al. Humanized mutant FUS drives progressive motor neuron degeneration without aggregation in 'FUSDelta14' knockin mice. Brain. 2017;140(11):2797-805.

11. Scekic-Zahirovic J, Sendscheid O, El Oussini H, Jambeau M, Sun Y, Mersmann S, et al. Toxic gain of function from mutant FUS protein is crucial to trigger cell autonomous motor neuron loss. EMBO J. 2016;35(10):1077-97. 
12. Scekic-Zahirovic J, Oussini HE, Mersmann S, Drenner K, Wagner M, Sun Y, et al. Motor neuron intrinsic and extrinsic mechanisms contribute to the pathogenesis of FUS-associated amyotrophic lateral sclerosis. Acta Neuropathol. 2017;133(6):887-906.

13. Marrone L, Drexler HCA, Wang J, Tripathi P, Distler T, Heisterkamp P, et al. FUS pathology in ALS is linked to alterations in multiple ALS-associated proteins and rescued by drugs stimulating autophagy. Acta Neuropathol. 2019;138(1):67-84.

14. Humphrey J, Birsa N, Milioto C, McLaughlin M, Ule AM, Robaldo D, et al. FUS ALS-causative mutations impair FUS autoregulation and splicing factor networks through intron retention. Nucleic Acids Res. 2020;48(12):6889-905.

15. Zhou Y, Liu S, Liu G, Ozturk A, Hicks GG. ALS-associated FUS mutations result in compromised FUS alternative splicing and autoregulation. PLOS Genet. 2013;9(10):e1003895.

16. Dini Modigliani S, Morlando M, Errichelli L, Sabatelli M, Bozzoni I. An ALSassociated mutation in the FUS 3'-UTR disrupts a microRNA-FUS regulatory circuitry. Nat Commun. 2014;5:4335

17. Mitchell JC, McGoldrick P, Vance C, Hortobagyi T, Sreedharan J, Rogelj B, et al. Overexpression of human wild-type FUS causes progressive motor neuron degeneration in an age- and dose-dependent fashion. Acta Neuropathol. 2013;125(2):273-88.

18. Scekic-Zahirovic J, Sanjuan-Ruiz I, Kan V, Megat S, De Rossi P, Dieterle S, et al. Cytoplasmic FUS triggers early behavioral alterations linked to cortical neuronal hyperactivity and inhibitory synaptic defects. Nat Commun. 2021;12:3028.

19. Dormann D, Rodde R, Edbauer D, Bentmann E, Fischer I, Hruscha A, et al. ALS-associated fused in sarcoma (FUS) mutations disrupt Transportinmediated nuclear import. EMBO J. 2010;29(16):2841-57.

20. Lagier-Tourenne C, Polymenidou M, Hutt KR, Vu AQ, Baughn M, Huelga SC, et al. Divergent roles of ALS-linked proteins FUS/TLS and TDP-43 intersect in processing long pre-mRNAs. Nat Neurosci. 2012;15(11):1488-97.

21. Burk U, Schubert J, Wellner U, Schmalhofer O, Vincan E, Spaderna S, et al. A reciprocal repression between ZEB1 and members of the miR-200 family promotes EMT and invasion in cancer cells. EMBO Rep. 2008;9(6):582-9.

22. Park SM, Gaur AB, Lengyel E, Peter ME. The miR-200 family determines the epithelial phenotype of cancer cells by targeting the E-cadherin repressors ZEB1 and ZEB2. Genes Dev. 2008;22(7):894-907.

23. Sephton CF, Tang AA, Kulkarni A, West J, Brooks M, Stubblefield JJ, et al. Activity-dependent FUS dysregulation disrupts synaptic homeostasis. Proc Natl Acad Sci U S A. 2014;111(44):E4769-78.

24. Gonzalez A, Mannen T, Cagatay T, Fujiwara A, Matsumura H, Niesman AB, et al. Mechanism of karyopherin-beta2 binding and nuclear import of ALS variants FUS(P525L) and FUS(R495X). Sci Rep. 2021;11(1):3754.

25. Baade I, Hutten S, Sternburg EL, Porschke M, Hofweber M, Dormann D, et al. The RNA-binding protein FUS is chaperoned and imported into the nucleus by a network of import receptors. J Biol Chem. 2021:100659.

26. Vance C, Scotter EL, Nishimura AL, Troakes C, Mitchell JC, Kathe C, et al. ALS mutant FUS disrupts nuclear localisation and sequesters wild-type FUS within cytoplasmic stress granules. Hum Mol Genet. 2013:22:2676-88.

27. Van Alstyne M, Tattoli I, Delestree N, Recinos Y, Workman E, Shihabuddin LS, et al. Gain of toxic function by long-term AAV9-mediated SMN overexpression in the sensorimotor circuit. Nat Neurosci. 2021;24:930-40.

28. Kino Y, Washizu C, Kurosawa M, Yamada M, Miyazaki H, Akagi T, et al. FUS/TLS deficiency causes behavioral and pathological abnormalities distinct from amyotrophic lateral sclerosis. Acta neuropathologica communications. 2015;3:24.

29. Orozco D, Tahirovic S, Rentzsch K, Schwenk BM, Haass C, Edbauer D. Loss of fused in sarcoma (FUS) promotes pathological Tau splicing. EMBO Rep. 2012;13(8):759-64

30. Ishigaki S, Fujioka Y, Okada Y, Riku Y, Udagawa T, Honda D, et al. Altered Tau Isoform Ratio Caused by Loss of FUS and SFPQ Function Leads to FTLD-like Phenotypes. Cell Rep. 2017;18(5):1118-31.

31. Yokoi S, Udagawa T, Fujioka Y, Honda D, Okado H, Watanabe $H$, et al. $3^{\prime} U T R$ Length-Dependent Control of SynGAP Isoform alpha2 mRNA by FUS and ELAV-like Proteins Promotes Dendritic Spine Maturation and Cognitive Function. Cell Rep. 2017;20(13):3071-84.

32. Ishigaki S, Sobue G. Importance of Functional Loss of FUS in FTLD/ALS. Front Mol Biosci. 2018;5:44

33. Huey ED, Ferrari R, Moreno JH, Jensen C, Morris CM, Potocnik F, et al. FUS and TDP43 genetic variability in FTD and CBS. Neurobiol Aging. 2012;33(5): 1016 e9-17.

34. Van Langenhove T, van der Zee J, Sleegers K, Engelborghs S, Vandenberghe R, Gijselinck I, et al. Genetic contribution of FUS to frontotemporal lobar degeneration. Neurology. 2010;74(5):366-71.
35. Broustal O, Camuzat A, Guillot-Noel L, Guy N, Millecamps S, Deffond D, et al. FUS mutations in frontotemporal lobar degeneration with amyotrophic lateral sclerosis. J Alzheimers Dis. 2010;22(3):765-9.

36. Flies $\mathrm{CM}$, Veldink JH. Chorea is a pleiotropic clinical feature of mutated fused-in-sarcoma in amyotrophic lateral sclerosis. Amyotroph Lateral Scler Frontotemporal Degener. 2020;21:309-11.

37. Yamashita S, Mori A, Sakaguchi H, Suga T, Ishihara D, Ueda A, et al. Sporadic juvenile amyotrophic lateral sclerosis caused by mutant FUS/TLS: possible association of mental retardation with this mutation. J Neurol. 2012;259(6): 1039-44.

38. Yan J, Deng HX, Siddique N, Fecto F, Chen W, Yang $Y$, et al. Frameshift and novel mutations in FUS in familial amyotrophic lateral sclerosis and ALS/ dementia. Neurology. 2010;75(9):807-14.

39. Merner ND, Girard SL, Catoire H, Bourassa CV, Belzil W, Riviere JB, et al. Exome sequencing identifies FUS mutations as a cause of essential tremor. Am J Hum Genet. 2012;91(2):313-9.

40. Tyzack GE, Luisier R, Taha DM, Neeves J, Modic M, Mitchell JS, et al. Widespread FUS mislocalization is a molecular hallmark of amyotrophic lateral sclerosis. Brain. 2019;142(9):2572-80.

41. Deng HX, Zhai H, Bigio EH, Yan J, Fecto F, Ajroud K, et al. FUSimmunoreactive inclusions are a common feature in sporadic and nonSOD1 familial amyotrophic lateral sclerosis. Ann Neurol. 2010;67(6):739-48.

42. Ikenaka K, Ishigaki S, Iguchi Y, Kawai K, Fujioka Y, Yokoi S, et al. Characteristic Features of FUS Inclusions in Spinal Motor Neurons of Sporadic Amyotrophic Lateral Sclerosis. J Neuropathol Exp Neurol. 2020;79:370-7.

43. Snowden JS, Hu Q, Rollinson S, Halliwell N, Robinson A, Davidson YS, et al. The most common type of FTLD-FUS (aFTLD-U) is associated with a distinct clinical form of frontotemporal dementia but is not related to mutations in the FUS gene. Acta Neuropathol. 2011;122(1):99-110.

44. Seelaar H, Klijnsma KY, de Koning I, van der Lugt A, Chiu WZ, Azmani A, et al. Frequency of ubiquitin and FUS-positive, TDP-43-negative frontotemporal lobar degeneration. J Neurol. 2010;257(5):747-53.

45. Josephs KA, Whitwell JL, Parisi JE, Petersen RC, Boeve BF, Jack CR Jr, et al. Caudate atrophy on MRI is a characteristic feature of FTLD-FUS. Eur J Neurol. 2010;17(7):969-75

46. Doi H, Koyano S, Suzuki Y, Nukina N, Kuroiwa Y. The RNA-binding protein FUS/TLS is a common aggregate-interacting protein in polyglutamine diseases. Neurosci Res. 2010;66(1):131-3.

47. Mori S, Honda H, Ishii T, Yoshimura M, Sasagasako N, Suzuki SO, et al. Expanded polyglutamine impairs normal nuclear distribution of fused in sarcoma and poly ( $\mathrm{rC}$ )-binding protein 1 in Huntington's disease. Neuropathology. 2019;39(5):358-67.

48. White MA, Kim E, Duffy A, Adalbert R, Phillips BU, Peters OM, et al. TDP-43 gains function due to perturbed autoregulation in a Tardbp knock-in mouse model of ALS-FTD. Nat Neurosci. 2018;21(4):552-63.

49. Sugai A, Kato T, Koyama A, Koike $Y$, Konno T, Ishihara T, et al. Nongenetically modified models exhibit TARDBP mRNA increase due to perturbed TDP-43 autoregulation. Neurobiol Dis. 2019;130:104534.

50. Koyama A, Sugai A, Kato T, Ishihara T, Shiga A, Toyoshima $Y$, et al. Increased cytoplasmic TARDBP mRNA in affected spinal motor neurons in ALS caused by abnormal autoregulation of TDP-43. Nucleic Acids Res. 2016:44(12):5820-36.

51. Ayala YM, De Conti L, Avendano-Vazquez SE, Dhir A, Romano M, $D^{\prime}$ Ambrogio A, et al. TDP-43 regulates its mRNA levels through a negative feedback loop. EMBO J. 2011;30(2):277-88.

52. Avendano-Vazquez SE, Dhir A, Bembich S, Buratti E, Proudfoot N, Baralle FE. Autoregulation of TDP-43 mRNA levels involves interplay between transcription, splicing, and alternative polyA site selection. Genes Dev. 2012;26(15):1679-84.

53. Bembich S, Herzog JS, De Conti L, Stuani C, Avendano-Vazquez SE, Buratti E, et al. Predominance of spliceosomal complex formation over polyadenylation site selection in TDP-43 autoregulation. Nucleic Acids Res. 2014;42(5):3362-71.

54. Suzuki H, Matsuoka M. hnRNPA1 autoregulates its own mRNA expression to remain non-cytotoxic. Mol Cell Biochem. 2017;427(1-2):123-31.

55. Vandesompele J, De Preter K, Pattyn F, Poppe B, Van Roy N, De Paepe A, et al. Accurate normalization of real-time quantitative RT-PCR data by geometric averaging of multiple internal control genes. Genome Biol. 2002; 3(7):research0034.1-.11.

\section{Publisher's Note}

Springer Nature remains neutral with regard to jurisdictional claims in published maps and institutional affiliations. 